\title{
Climate sensitivity of global terrestrial net primary production (NPP) calculated using the reduced-form model NNN
}

\author{
O. Moldenhauer*, M. K. B. Lüdeke \\ Questions-Project, Potsdam Institute for Climate Impact Research, PO Box 601203, 14412 Potsdam, Germany
}

\begin{abstract}
In order to assess the potential impact of climate change on terrestrial equilibrium net primary production (NPP), information about the sensitivity of terrestrial NPP to climate change is needed. A novel approach to the definition of climate sensitivity is introduced; it does not depend on specific (and uncertain) scenarios, but rather describes the worst-case climate sensitivity of NPP, as measured by the magnitude of the gradient of NPP, as a function of the climate variables. The metric in climate space necessary for the determination of the gradient is calculated using the existing spatial variation of the climate variables as a measure of the potential for climate change, taking into account the unchanging determinants of the climate-latitude and altitude. The current correlations between the climate variables are preserved using principal component analysis. The resulting map of global NPP sensitivity shows especially high values, e.g. in the US Midwest, southern Africa, Australia, western Kazakhstan, the Maghreb and Spain. The sensitivity is aggregated to the country level, excluding the effects of the very insensitive deserts, in order to make these results applicable for policy analysis. The reduced-form model 'NNN' predicts annual terrestrial NPP of potential natural vegetation in equilibrium on the basis of a climatology including monthly values for temperature, precipitation and light. The very short computing time of this model is a prerequisite for the above-described multidimensional sensitivity study. To construct NNN, the average of the global NPP results of 7 advanced climatology-driven functional vegetation models was used to obtain a 'best guess' NPP field at a $0.5^{\circ} \times 0.5^{\circ}$ spatial resolution. With the underlying climatology (36 values for monthly mean temperature, precipitation and light intensity per grid element), 62483 points of an $\mathbb{R}^{36} \rightarrow \mathbb{R}^{1}$ mapping are defined. A subset of these was used to train a neural network yielding a good reproduction of the spatial pattern with a mean absolute error of $0.026 \mathrm{~kg} \mathrm{C} \mathrm{m}^{-2} \mathrm{yr}^{-1}$, which is significantly less than the mean uncertainty of the NPP average (mean absolute deviation: $0.097 \mathrm{~kg} \mathrm{C} \mathrm{m}^{-2} \mathrm{yr}^{-1}$ ). Furthermore, it is shown that the simple model calculates moisture-limited regions correctly, indicating that functional properties of the original models are reproduced. We hope with the NNN to make a contribution to other research which needs a very fast reduced-form NPP model. The NNN model is accessible in FORTRAN or as a C-subprogram available at: http://www.pik-potsdam.de/ oliver/NPP.html.
\end{abstract}

KEY WORDS: Net primary production (NPP) - Climate change impact · Vulnerability · Neural networks $\cdot$ NNN $\cdot$ Principal component analysis $\cdot$ Climate sensitivity

Resale or republication not permitted without written consent of the publisher

\section{INTRODUCTION}

The response of the net primary production (NPP) of global vegetation to climate change is of central concern for global carbon cycling and climate impact research.

*E-mail: oliver@pik-potsdam.de
With respect to the first point, estimation of the feedback of the global terrestrial ecosystems via net carbon release or storage of atmospheric $\mathrm{CO}_{2}$ concentrations is essential for any climate prognosis concerning greenhouse effects (e.g. Kohlmaier et al. 1991), as well as for paleoclimatic reconstructions (e.g. Levis et al. 1999). Here, in addition to heterotrophic respiration, 
changes in NPP are responsible for ecosystem production changes. Changes in other vegetation properties relevant to climate feedback, such as evapotranspiration or leaf area index, are also closely related to NPP. On the other hand, in the context of systemic climate impact research, the NPP of terrestrial natural vegetation is an important indicator for assessing the role of possible future climate change for both natural and managed ecosystems on a global scale (e.g. Alcamo 1994, Cassel-Gintz et al. 1997, Lüdeke et al. 1999). Here, global problems such as food security and desertification are addressed.

An alternative to the mass flux oriented approach used in this study, attempts have been made to describe the response of vegetation in terms of structural changes using climatic envelopes for discrete vegetation types or biomes (e.g. Prentice et al. 1992). This provides only a relatively rough picture of climate impact on vegetation, since, for example changes in NPP or carbon stock may be considerable, even with no change in vegetation type. However, these models were used in coupled climate-vegetation modeling, due to their simplicity and fast computing time (e.g. de Noblet et al. 1996, Kubatzki \& Claussen 1998). A recent development in vegetation modeling is the combination of the flux/state and the biome approaches, mostly via the competition of plant functional types (e.g. Foley et al. 1996), a way that appears straightforward but carries with it tremendous difficulties.

We now face 2 major uncertainties in projecting NPP under climate change: (1) uncertainty with respect to the description of dependence of NPP on climate; and (2) uncertainty with respect to climate predictions. Both uncertainties will be addressed explicitly in the present study, with no subjective choice of a best NPP model or a best climate forecast.

Uncertainty (1) is clearly documented by the results of an intercomparison of 17 state-of-the-art vegetation models (Cramer et al. 1999), which shows considerable differences in basic model assumptions and in the global NPP fields calculated for the existing climate. Both differences indicate that the mapping of climate impact on NPP obviously requires more precision. In Section 2 of this paper, we propose a pragmatic 2-step procedure for dealing with this scientific uncertainty: (1) the global NPP fields calculated for the current climate by several mechanistic models are to be averaged to obtain a 'best guess' NPP-field characterized by the minimum expectation value for errors; (2) an artificial neural network (ANN) which reproduces this 'best guess' NPP field from a climatology of monthly normals for temperature, precipitation and insolation is to be trained. The result is the Neural Net NPP model (NNN), which allows fairly rapid calculation of NPP from 36 climate input variables, while to some extent reproducing the 'wisdom' of the mechanistic models. Its validity is tested by identifying moisture-limited regions using the NNN and comparing them to an independent measure from a functional soil water model.

Uncertainty (2) is illustrated by the study of Ciret \& Henderson-Sellers (1997), in which the differences between the climate simulations of several global circulation models (provided by the Model evaluation Consortium for Climate assessment) with respect to their importance for the determination of vegetation type on the basis of simple biome models were investigated. The discrepancies in the computed vegetation distribution were considerable (agreement on less than $50 \%$ of land area) - so one would expect similarly poor agreement on calculated NPP fields (see, e.g. Melillo et al. 1993). This provides the motivation to perform a local sensitivity analysis of NPP in climate space, rather than comparing NPP fields calculated from climate predictions.

This sensitivity analysis (Section 3 ) is carried out in 3 steps: (1) Aspects of climate elements which will be constant under climate change, e.g. the influence on temperature of the control variables altitude and insolation at the top of the atmosphere, have to be 'subtracted'. (2) The resulting climate variables which are now subject to change must be scaled (e.g. to make the NPP change caused by precipitation and that caused by temperature comparable); moreover, they will not change totally independently from one another (e.g. temperature change in January and February will not be independent). This is guaranteed by a principal component transformation of climate space and by applying the z-norm. (3) Finally, the absolute value of the gradient of NPP with respect to the transformed climate is calculated as a measure of climate sensitivity, indicating the maximum 'slope' of NPP, realized by the respective 'worst-case' direction of climate change.

In Section 4, the sensitivity results are discussed, and areas of particular NPP climate sensitivity are identified.

\section{NNN: A STATISTICAL MODEL FOR NPP}

\subsection{A ‘best guess' global equilibrium NPP field}

To be able to construct our NPP-model NNN, we first need a 'best guess' NPP field. At the present stage of functional global vegetation modeling, several different approaches exist in parallel, and since there is no complete consensus on the importance of the ecological and ecophysiological processes involved, with even more disagreement on their parameterization, the modeling results of different work groups, including their global equilibrium NPP fields, vary to some 
extent. Due to the lack of sufficient ground truth data (only some hundreds of NPP observations for the whole globe; Olsen et al. 1997), the results of all these models have at present to be considered equally likely. The uncertainty is enhanced by the spatial disaggregation problem (point measurements vs modeled averages for areas of about $1000 \mathrm{~km}^{2}$ ).

In order to make optimal use of this present state of knowledge, we: (1) took the arithmetic average of the results of several vegetation models, so as to some extent overcome the insufficiencies of the single models; and (2) quantified the disagreement between the model results by the standard deviation of the model average, to assess the degree of expert consensus.

Assuming a complete, although unknown, set of observations, it is easy to prove that, by taking this average result instead of one arbitrarily chosen single model result, one obtains:

- a smaller mean absolute error,

- a smaller mean square error, and

- a smaller maximum absolute error

at every pixel, compared with the respective expectation value (under rather unlikely conditions, the errors could be equal). Short proofs for these 3 properties are given in Appendix A.

We would like to stress here that this procedure is not an attempt to replace the necessary scientific clarification process regarding the correct method for modeling global vegetation; rather, it is an attempt to make the present state of knowledge with respect to an annual global equilibrium NPP field accessible.

To obtain a 'best guess' NPP field in the sense mentioned above, we averaged the equilibrium NPP results of 7 different global vegetation models which were all driven by the same climatology, and some of them additionally by further global parameter fields which are constant in time.
Table 1. Vegetation models used in the averaging process

\begin{tabular}{|ll|}
\hline Model & Source \\
\hline HRBM & Esser et al. (1994) \\
BIOME3 & Haxeltine \& Prentice (1996) \\
PLAI & Plöchl \& Cramer (1995a,b) \\
SILVAN & Kaduk \& Heimann (1996) \\
DOLY & Woodward et al. (1995) \\
FBM & Lüdeke et al. (1994) \\
& Kohlmaier et al. (1997) \\
CENTURY & Schimel et al. (1996) \\
\hline
\end{tabular}

For this purpose:

- we used models which deal with potential natural vegetation, excluding effects of direct human impact (e.g. land use change) which are not predictable by using climate data only; hence, models driven by observed global fields of vegetation properties (like NDVI fields) are not suitable for our purpose;

- models should be prognostic to some extent, at least for intermediate time scales (decades), i.e. the dynamics of the main vegetation properties must be calculated internally.

In Table 1 , the 7 modeling groups which provided recent global annual NPP results for the present study are listed. We by no means wish to imply that the models chosen are the only acceptable ones which fulfill the above conditions - the choice also depends on practical aspects (global model results based on common driving variables being on hand or simple to produce). In general the proposed procedure must always have a transient and to some extent preliminary character.

In Fig. 1, we show the result of the averaging process, which amounts to a total global NPP of $54.40 \mathrm{GtC}$ $\mathrm{yr}^{-1}$, and in Fig. 2, we show the standard deviation of

Fig. 1. Averaged equilibrium net primary production (NPP ${ }^{\text {avg }} ; \mathrm{kgC}$ $\left.\mathrm{m}^{-2} \mathrm{yr}^{-1}\right)$

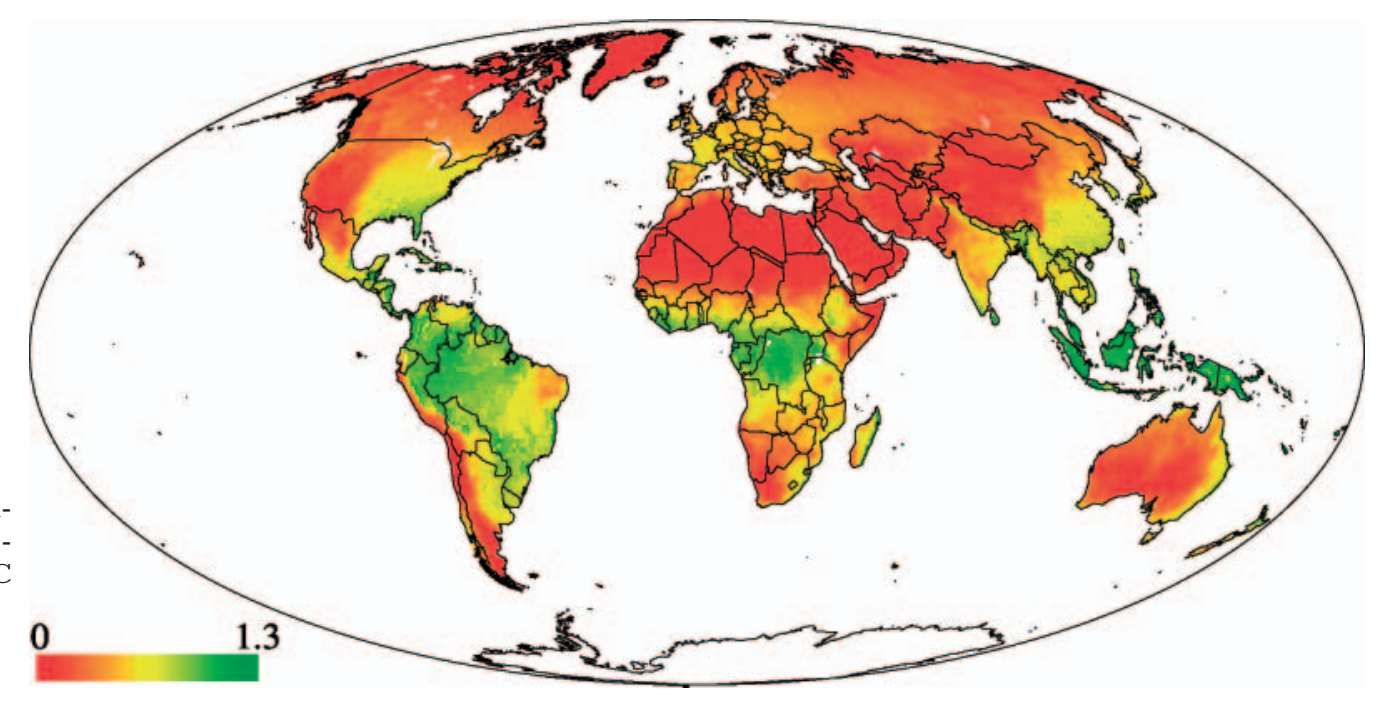




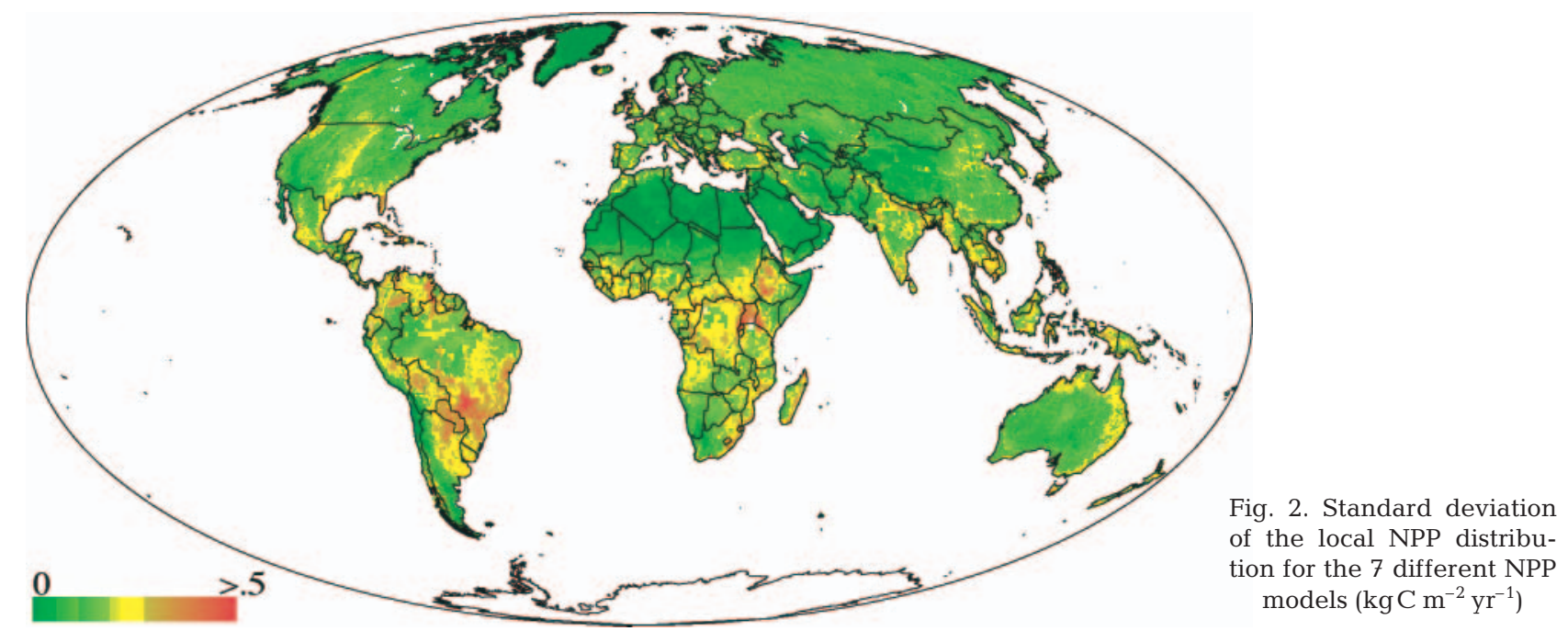

the local NPP distribution. Most of the areas of poor model consensus (Fig. 2) show up at the transition zones between different climatic regimes. In terms of the Köppen-Trewartha classification (Köppen 1931, Trewartha 1968), the western part of Ethiopia is characterized by the transition from the Tropical Humid, Winter Dry Savanna climate (Aw) over the Warmer Dry Steppe climate (BSh) to the Warmer Dry Desert climate (BWh) and shows a high standard deviation; the same occurs between the Warmer Humid, Constantly Moist Humid Subtropical climate (Caf) in Argentina, Paraguay and Brazil on the one hand and the Dry Steppe (BS) or the Tropical Humid, Savanna climate (Aw) on the other hand. Another region of poor model consensus is located around the northern borders of Bhutan, Arunachal Pradesh (India) and Myanmar, which is characterized by the transition between the Polar Tundra climate (ET) and the Warmer Humid, Subtropical Winter Dry climate (Caw). Other regions of high stan- dard deviation, e.g. the area northwest of Lake Victoria and areas in the eastern part of Colombia or Western Australia, cannot be assigned to the Köppen classification of climatic transition zones.

The global mean of the local absolute deviation amounts to $0.097 \mathrm{kgC} \mathrm{m}^{-2} \mathrm{yr}^{-1}$. Despite this rather poor consensus, compared to the average result of $0.345 \mathrm{kgC} \mathrm{m}^{-2} \mathrm{yr}^{-1}$, the global equilibrium NPP field shown in Fig. 1 has to be regarded as the 'best guess' result, according to the above arguments.

\subsection{Predicting the 'best guess' NPP field from climate data with an ANN}

The vegetation model results considered in the averaging process above were obtained by means of a widely-used climatology, the CLIMATE2.1 database (Leemans \& Cramer 1991, W. Cramer pers. comm.,

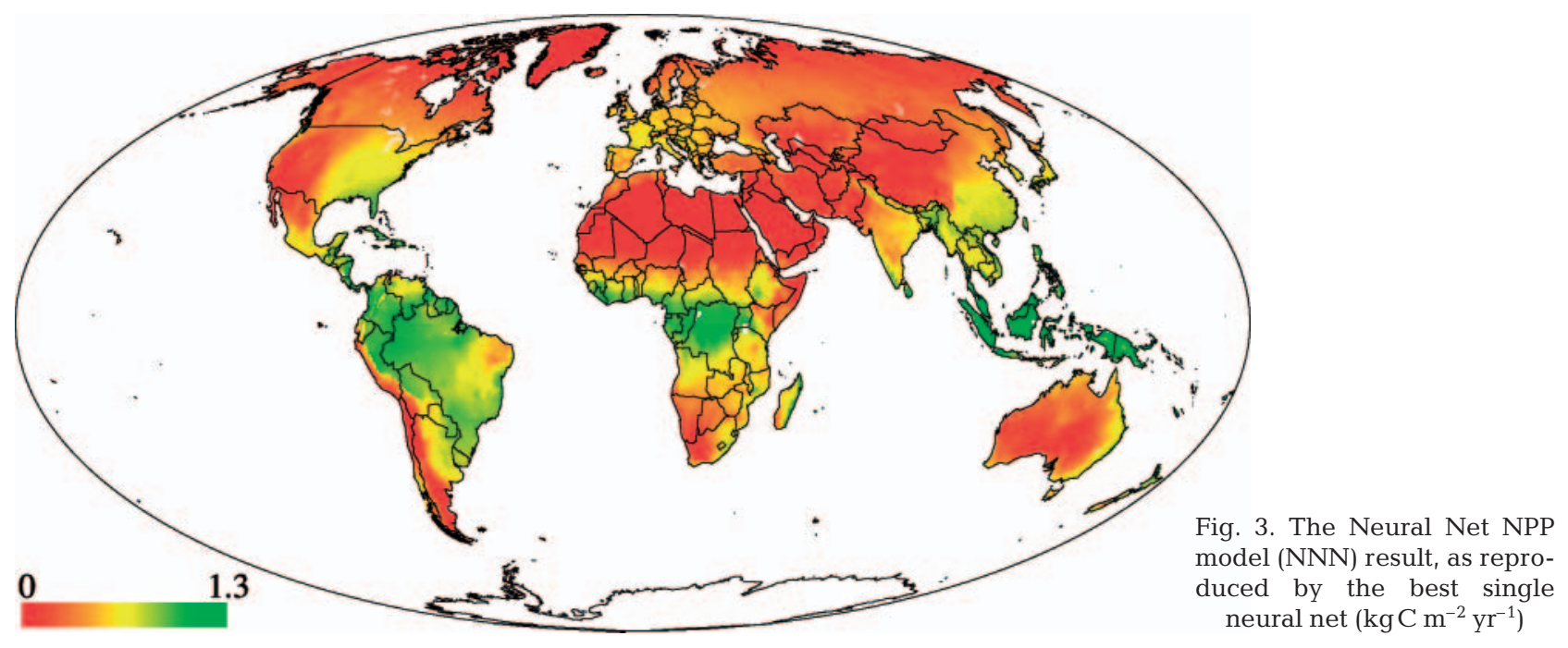


1997), consisting of 36 climate variables - 12 mean monthly temperatures, 12 monthly precipitations and 12 mean monthly light intensities (originating from relative sunshine data) - on a $0.5^{\circ} \times 0.5^{\circ}$ grid of the terrestrial surface of the Earth (excluding the Antarctic), for a total of 62483 grid elements. To make the northern and southern hemispheres comparable, the variables for the southern hemisphere have been shifted by 6 mo, e.g. New Zealand's January is mapped onto July in all our calculations.

These 36 input variables are sufficient to reproduce the 'best guess' NPP field by means of a simple parameterized ANN model with a mean accuracy significantly better than the mean model consensus. The 12519 grid elements representing North America were taken out of the parametrization procedure and used as a test set. The remaining 49964 grid elements were used to train a 3-layer feed-forward neural network with 36 input nodes (for the climate elements), 1 hidden layer with 21 nodes, 1 output node (for the NPP) and additional direct connections from the input nodes to the output node. This ANN is defined by its structure, the so-called activation function and 835 weights and offsets (for details, see Appendix B). The relatively high number of parameters of the ANN originates from the high dimension of the input space spanned by climate and the necessity of considering non-linear properties. These parameters were optimized by a steepest descent procedure to reproduce the NPP field of the training set with a minimum mean square error ('standard back-propagation'). Since this optimization algorithm is stochastic (especially due to the random initial values) and there is a multitude of local optima, we applied the optimization algorithm 30 times and took the best of these runs (as defined by the least square error in the test set). The optimum of parameterization was fixed, and defines the Neural Net work NPP model 'NNN'. NNN was applied to the test set (North America), which was 'unknown' for the training procedure.

After several experiments with respect to the network's structure using, for example 2 hidden layers or radial basis functions, we obtained a mean absolute error of $0.025 \mathrm{kgC} \mathrm{m}^{-2} \mathrm{yr}^{-1}$ for the training set and $0.028 \mathrm{~kg} \mathrm{C} \mathrm{m}^{-2} \mathrm{yr}^{-1}$ for the test set. The complete result of the optimum neural net using the 36 climate elements as input is displayed in Fig. 3 (an enlargement for a part of Europe is shown in Fig. 4), showing a very good reproduction of the 'best guess' NPP field by the NNN model, with a mean absolute error of $0.026 \mathrm{kgC}$ $\mathrm{m}^{-2} \mathrm{yr}^{-1}$; this is significantly smaller than the mean absolute deviation of $0.097 \mathrm{kgC} \mathrm{m}^{-2} \mathrm{yr}^{-1}$, which describes the model consensus. The total global NPP of the fit amounts to $55.43 \mathrm{GtC} \mathrm{yr}^{-1}(101.9 \%$ of the target). To compare the uncertainties of the NNN model

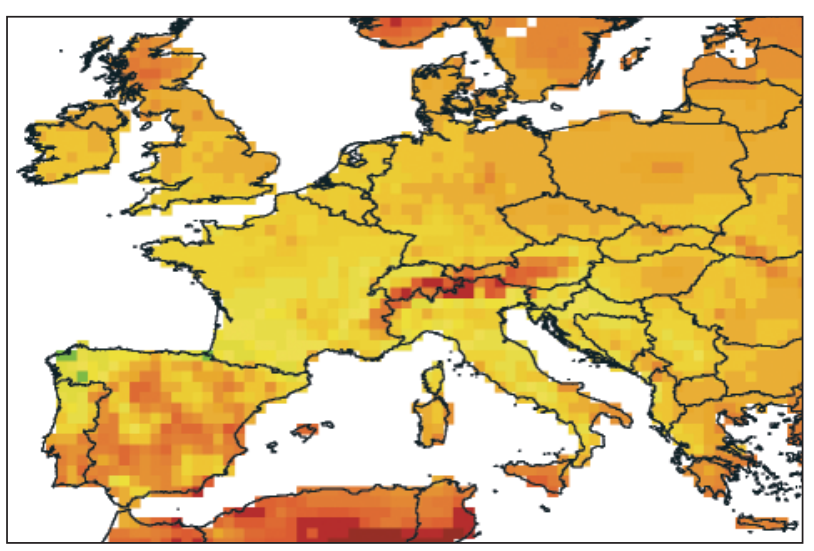

Fig. 4. An enlargement of Fig. 3 showing a part of Europe

with the degree of consensus occurring in the NPP averaging process in more detail, the integrated distributions of root mean square error (which is in this simple case the absolute error) and the standard deviation, $\sigma$, are displayed in Fig. 5 and show significantly fewer grid elements for every error interval. To estimate the stochastic uncertainty in the training procedure of the net, we took the 15 best nets (out of a total of 30) and averaged the standard deviation at each pixel of the 15 different results of these nets over the whole world. We arrived at $0.011 \mathrm{kgC} \mathrm{m}^{-2} \mathrm{yr}^{-1}$, which is significantly less than the mean difference between the NNN and the 'best guess' NPP, indicating that this optimization error is comparatively small.

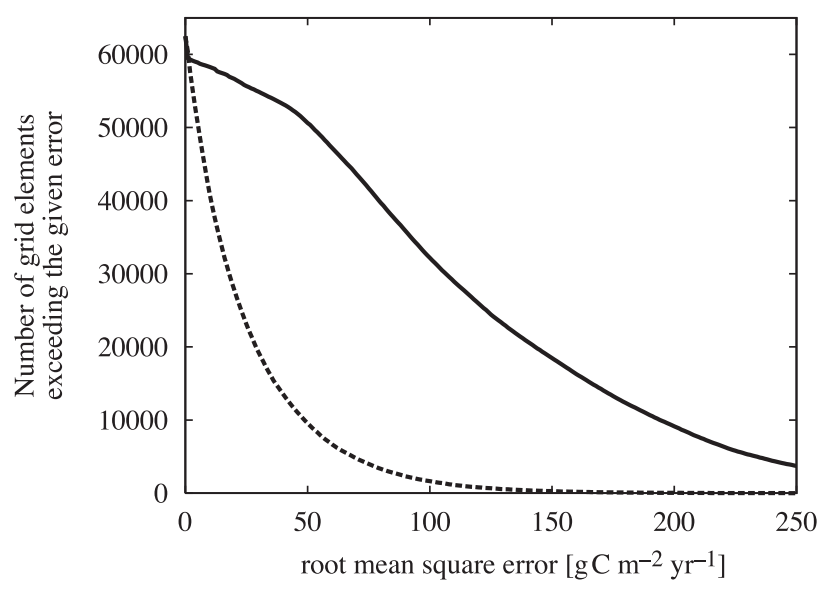

Fig. 5. Comparison of the cumulative distribution of the root mean square error of the NNN (which equals the absolute error in this case, as only 1 datum pixel ${ }^{-1}$ is considered) (dashed line) with the cumulative distribution of the standard deviation of the NPP averaging process (solid line). $x$-axis: value of the root mean square error or standard deviation, $\sigma$, respectively. $y$-axis: number of grid-points with root mean square errors or $\sigma$ greater than $x$ 
At this point we want to stress that due to the statistical character of the modeling approach the NNN model could produce somewhat unrealistic results for climates which are very different compared to the existing ones (e.g. a monthly oscillating temperature with an amplitude of $30 \mathrm{~K}$ ).

To make the model accessible, we provide a short piece of computer source code (FORTRAN or C-subprogram, available at: www.pik-potsdam.de/ oliver/ NPP.html) which contains the ANN structure, the transition function and the weighting factors.

\subsection{Testing NNN}

The crucial test for a statistical model such as the one described here is to reproduce data not used in the training process. Instead of using randomly sampled grid elements for this purpose, we chose a whole region (North America) as a test set, which is spatially separated from the grid elements used for training, so that there is no interdependence between the test climate and the training climate due to the interpolation done to produce the CLIMATE2.1 database.

The spatial pattern of the deviation of the neural net fit from the average NPP field shows a reasonable although somewhat worse reproduction of North America as compared to the training set (Fig. 6), in spite of the existence of several different vegetation zones and transitional regions. Therefore we are confident that the model can be applied to climates for which it is not directly trained, which is a condition for its application in the analysis of climate change.

It is not self-evident that empirical models such as the present ANN, or any other statistical method, can reproduce a correct result for the right reason, such as a low NPP value caused by moisture limitation (i.e. a specific combination of annual precipitation and temperature course) rather than using other, nonfunctional, correlations.

As a test of the ability of the NNN presented here to reproduce functional properties in this sense, we used it to identify regions where NPP is limited by precipitation. To achieve this, we increased the monthly precipitation values by $100 \mathrm{~mm} \mathrm{mo}^{-1}$ on each pixel, and computed the relative increase in NPP. One would expect that an increase in NPP would be calculated in precipitation-limited regions, while in regions governed by other limiting factors, the resulting NPP would remain constant. The result is displayed in Fig. 7, where increased values indicate increased moisture limitation. This result can be compared with an aridity coefficient, $\alpha$ (Fig. 8), which describes the annual sum of the daily ratios between actual and potential annual evapotranspiration as obtained from a functional soil water model (Prentice et al. 1992). The main spatial patterns of $\alpha$ are very similar to those calculated with NNN. The greater gradients in the transition zones between arid and non-arid regions in the case of NNN are to be expected as a result of the non-linear response of NPP to the soil moisture regime.

\section{PERFORMING THE LOCAL SENSITIVITY ANALYSIS}

As previously demonstrated (e.g. in Lüdeke et al. 1999) the climate change prognosis produced by GCM modeling, despite the GCM's high scientific sophistication, shows such a degree of uncertainty that results of impact analyses become, at least partly, questionable. Therefore, we are seeking a method for describ-

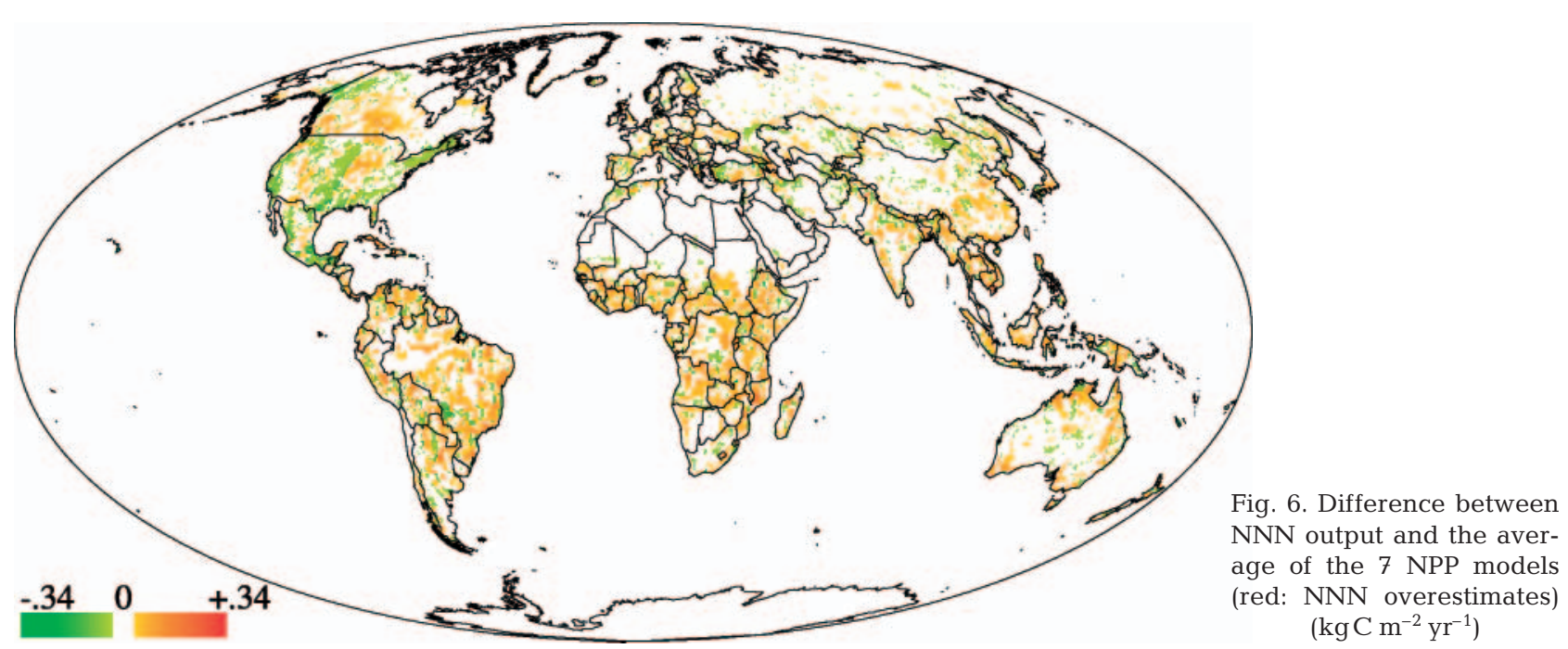


Fig. 7. Water limitation of NPP as calculated by NNN: the factor of the relative NPP increase in response to additional precipitation

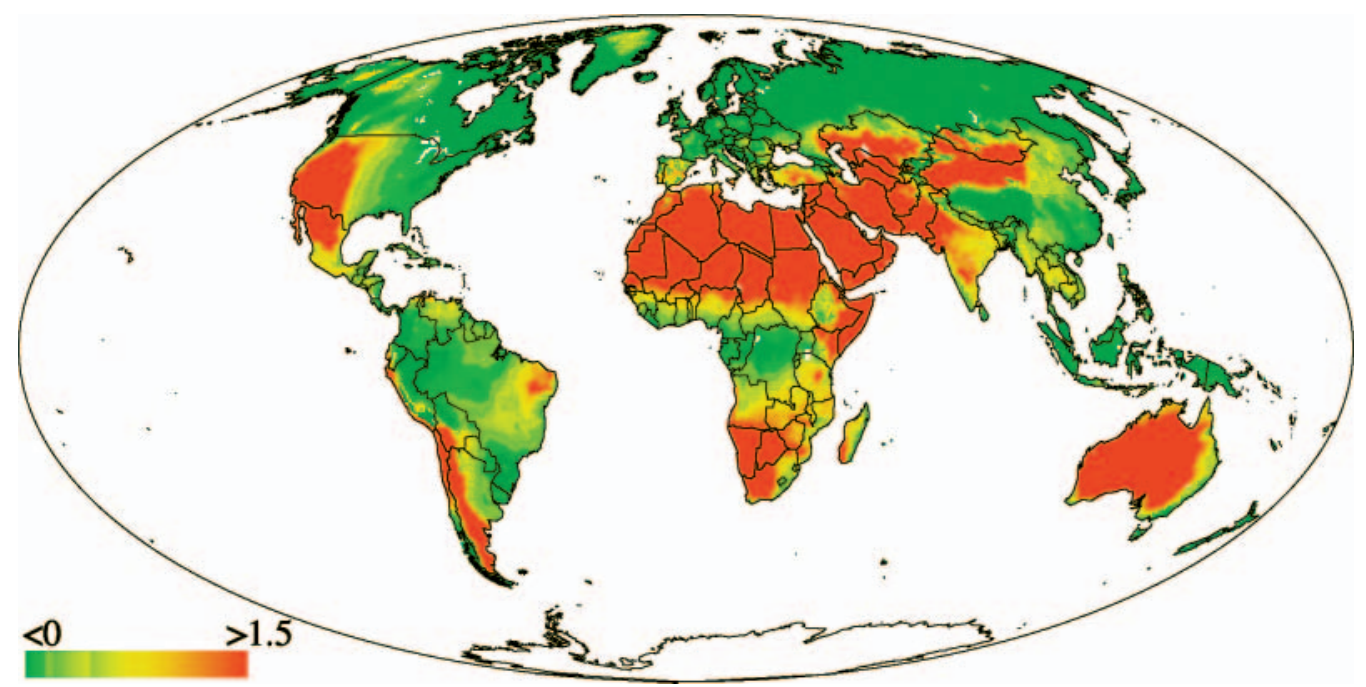

ing sensitivity to climate change independent of a given scenario.

The first question to address concerns the direction in which we should vary the climate for the purposes of our calculations. It would appear prudent to choose the direction promising the maximum possible change in NPP, i.e. the measure we propose for climate sensitivity is the maximum rate of change in NPP at a given point in climate space, when climate is varied by a given, tiny amount in any possible direction. For example, this maximum change could constitute increased insolation, precipitation and temperature with an emphasis on summer precipitation in one area and an increase mainly in spring and autumn temperature in another. Mathematically speaking, we define the magnitude of the gradient of the 36-dimensional NPP function defined by NNN as the climate sensitivity of NPP.

\subsection{Correction of the climate for the effects of altitude and insolation}

The current variation of the climate variables over the globe is controlled to a large degree by factors that are constant over a time scale far exceeding anthropogenic influence. Therefore, it is useful to first remove the most important of these influences, which are undoubtedly the influences of the altitude of each pixel and insolation at the top of the atmosphere (which is a fixed function of latitude) on temperature. To identify this influence, we fitted the temperature data for each month to a simple linear model:

$$
T=\mathrm{C}+\alpha_{\text {total }} S_{\text {total }}+\alpha_{\text {Dec }} S_{\text {Dec }}+\beta h
$$

thus predicting the monthly mean temperature $T$ as a function of the sum of the mean monthly insolations
Fig. 8. $1-\alpha$; 0: humid, 1 : arid. The aridity coefficient $\alpha$ is obtained from a functional soil water model

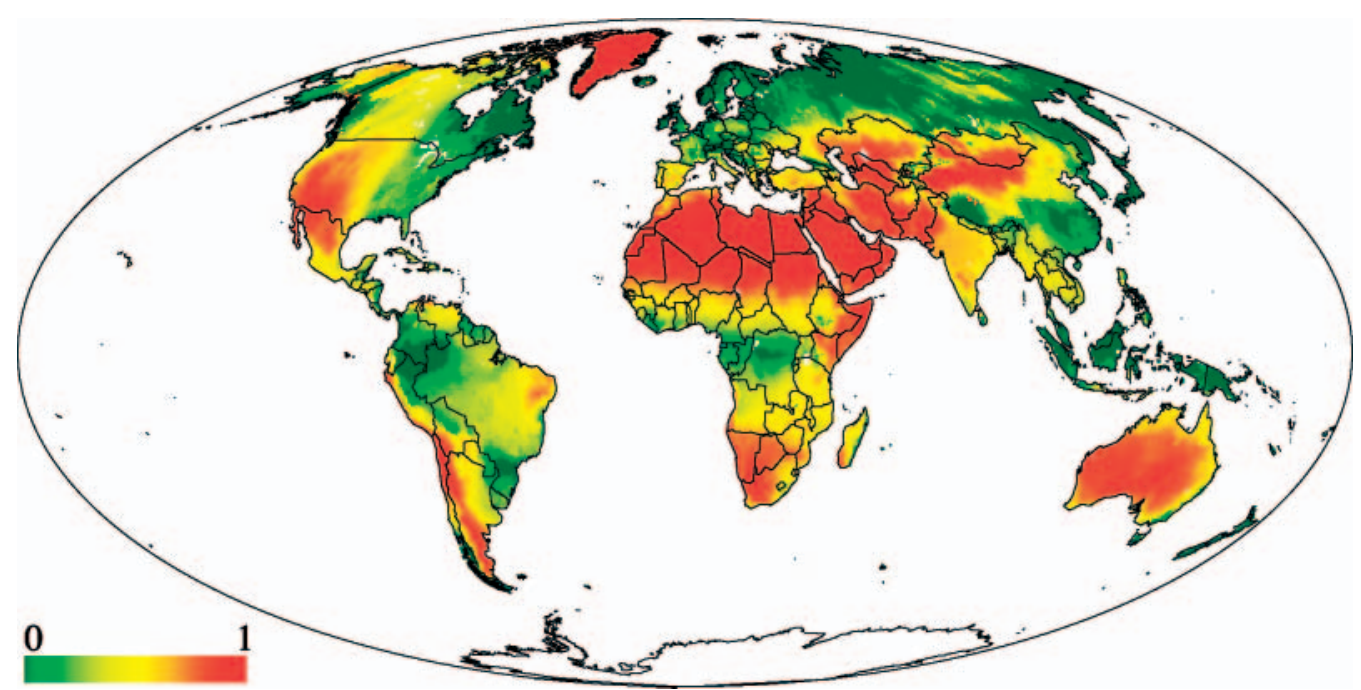


$s_{\text {total, }}$ altitude $h$ and the December insolation $s_{\text {Dec }}$. The latter gives us important information about the annual insolation cycle, which is much stronger at higher latitudes. The altitude data used is the ETOPO5 global digital elevation data set with a $5^{\prime} \times 5^{\prime}$ resolution (USNGDC 1988), averaged over $0.5^{\circ} \times 0.5^{\circ}$ pixels. The coefficients $\alpha_{\text {total, }} \alpha_{\text {Dec }}$ and $\beta$ have been determined by a simple linear least-square fit of the climate data for each month and can be found, together with the linear correlation coefficients $\mathrm{r}^{2}$, in Table 2 . The distribution of the data points compared to the linear model is depicted for January, as an example, in Fig. 9. The remaining undeclared variation is due to the more complex determinants of the climate system, which can be subject to anthropogenic climate change. Therefore, for the further discussion of the variation of climate, we will use the difference between the temperature contribution as defined by Eq. (1) and the actual temperature, as shown, for January, as an example, in Fig. 10.

Like temperature, insolation at the surface is strongly influenced by the geometry of the Earth and its movements. Therefore, for our considerations here, we use relative sunshine time, instead of insolation, as the input variable for NNN.

\subsection{Finding the right metric for variations in climate space}

The next question concerns the metric in our 36dimensional climate space, i.e. how do we define a common measure for the units of temperature, precipitation and relative sunshine? To answer this question, some assumptions must be made as to the likelihood of certain changes in climate. Our proposal is to take the current spatial variation in these climate variables throughout the world as an approximate measure of this likelihood.

Table 2. Coefficients for Eq. (1) for the different months, together with the linear correlation coefficient $r^{2}$. PAR: photosynthetically active radiation

\begin{tabular}{|lccccc|}
\hline Month & $\begin{array}{c}\mathrm{C} \\
\left({ }^{\circ} \mathrm{C}\right)\end{array}$ & $\begin{array}{c}\alpha_{\text {total }} \\
\left({ }^{\circ} \mathrm{C} \mathrm{m}^{2} \mathrm{~d}[\mathrm{Wh} \mathrm{PAR}]^{-1}\right)\end{array}$ & $\begin{array}{c}\alpha_{\text {Dec }} \\
\left({ }^{\circ} \mathrm{C} \mathrm{m}^{-1}\right)\end{array}$ & $\mathrm{r}^{2}$ \\
\hline Jan & -56.8 & 0.00069 & 0.00372 & -0.00436 & 0.912 \\
Feb & -62.2 & 0.00084 & 0.00259 & -0.00403 & 0.926 \\
Mar & -72.4 & 0.00118 & -0.00038 & -0.00414 & 0.947 \\
Apr & -67.2 & 0.00128 & -0.00252 & -0.00414 & 0.948 \\
May & -49.1 & 0.00111 & -0.00294 & -0.00386 & 0.922 \\
Jun & -35.9 & 0.00100 & -0.00354 & -0.00379 & 0.877 \\
Jul & -33.8 & 0.00104 & -0.00449 & -0.00396 & 0.865 \\
Aug & -38.6 & 0.00109 & -0.00452 & -0.00417 & 0.911 \\
Sep & -45.0 & 0.00109 & -0.00338 & -0.00444 & 0.947 \\
Oct & -53.7 & 0.00107 & -0.00179 & -0.00458 & 0.956 \\
Nov & -60.3 & 0.00098 & 0.00045 & -0.00456 & 0.931 \\
Dec & -57.4 & 0.00076 & 0.00282 & -0.00461 & 0.914 \\
\hline
\end{tabular}

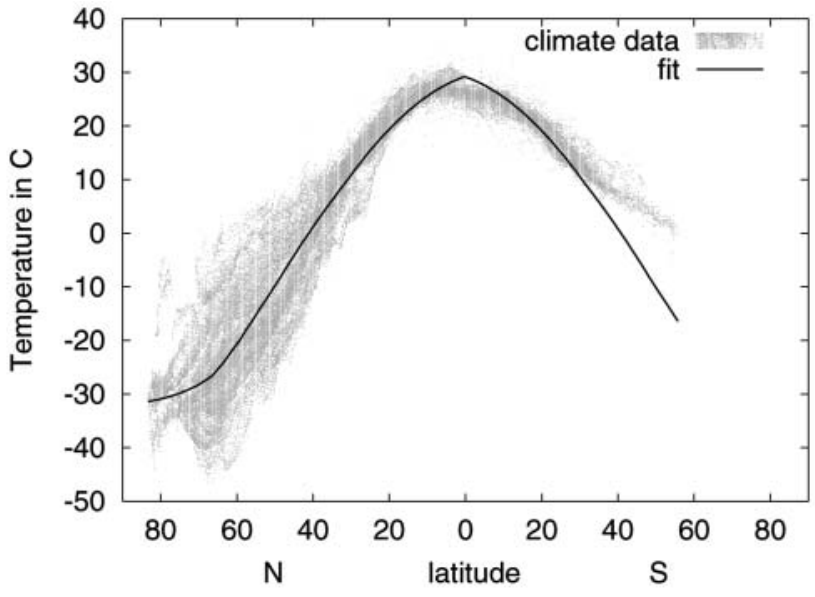

Fig. 9. The contribution of insolation to January temperature (for the southern hemisphere a 6 mo shift is applied) at sea level as estimated by Eq. (1) compared to the mean-altitudecorrected January temperatures $T^{\prime}$ derived by $T^{\prime}=T_{\mathrm{C}}-\beta h$ from the mean January temperature $T_{\mathrm{c}}$ from the CLIMATE2.1 database (dots). The greater variation in the northern latitudes is due to greater land mass generating more inhomogeneous temperature regimes (e.g. continental vs maritime climate). Due to the relative small number of land pixels in the south the overall fit is reasonable only north of about $35^{\circ} \mathrm{S}$, where it shows the influence of insolation on temperature

The simplest approach would be to weigh each variable according to the standard deviation $\sigma$ it exhibits throughout the world ( $z$-norm). However, since we find very high correlations between some climate variables (e.g. between January temperature and February temperature) it would seem to make little sense to vary them independently of one another; this would alter the correlations between them, which would contradict our assumption that climate change potential is related to today's spatial variation. We therefore leave the space of simple climate variables after the $z$-transformation and enter into the realm of principle component space, which provides a statistically more natural description of the climate. In other words, we calculate the principal components of the existing climate and transform the climate data into this basis. Thereby we ensure that changes along these axes are in accordance with today's correlation between the different variables and that the current spatial distribution in each variable has the identical $\sigma$ of 1 . To illustrate this double transformation, a 2-dimensional example is shown in Appendix C.

In our calculation, principal component analysis (PCA) ensures that the correlations between different variables are preserved. In contrast to many other applications of PCA, we do not use it here for data reduction purposes, since all components are retained, albeit weighted, as described above, by the degree of their explanation of the variance. 
Fig. 10. Deviation of the actual mean January temperature from the expected temperature according to height and latitude, constructed by subtracting the temperature resulting from Eq. (1) from the temperature found in CLIMATE2.1. The effect of ocean currents and especially of the Gulf Stream, warming western Europe considerably compared to other regions of the same latitude and altitude, can be seen quite clearly

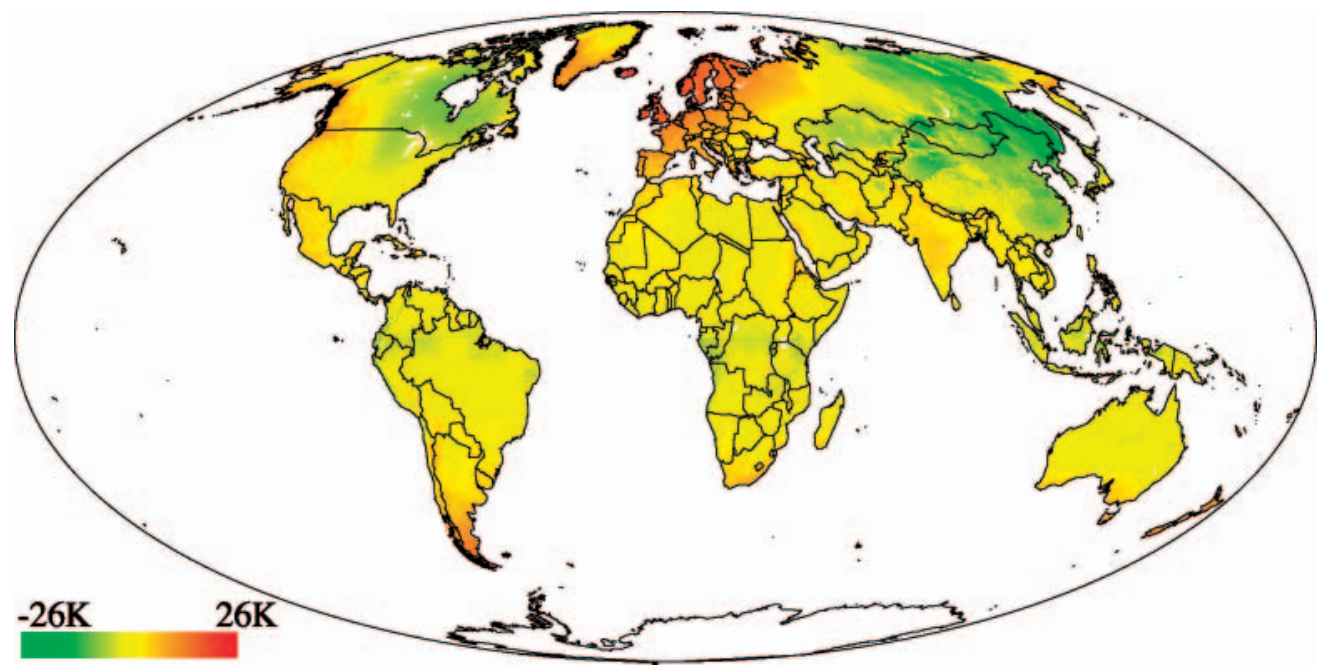

\subsection{Resulting sensitivity of NPP}

As discussed before, we propose to index climate sensitivity by calculating the gradient in principal component space:

$$
\begin{aligned}
S= & \left|\nabla_{P C} \mathrm{NPP}(\mathbf{C})\right| \\
& \sqrt{\sum_{i=1}^{36}\left(\frac{\partial \mathrm{NPP}}{\partial \mathrm{PC}_{i}}\right)^{2}} \\
& \sqrt{\sum_{i=1}^{36}\left(\sum_{j=1}^{36} \frac{\partial \mathrm{NPP}}{\partial C_{j}} \frac{\partial C_{j}}{\partial \mathrm{PC}_{i}}\right)^{2}}
\end{aligned}
$$

Here, $S$ is the climate sensitivity, C contains the 36 original climate variables corrected for the influence of altitude and latitude, and $\mathrm{PC}_{i}$ are the 36 principal components on which climate space has been projected, as discussed above. According to this calculation, $S$ is the largest slope of the NPP function in principal component space. As discussed in Section 2.2, the ANN generates 15 different instances of the NPP function. The gradients derived from these different instances were averaged; the resulting map of global climate sensitivity of NPP is shown in Fig. 11 (an enlargement for a part of Europe is shown in Fig. 12). The standard deviation of the set of 15 different gradients at a given pixel can be viewed as a measure for the uncertainty of the gradient due to uncertainties in optimizing the statistical model NNN, and is shown in Fig. 13.

The most sensitive areas are southern and eastern Africa, in the Maghreb and Spain, in western Kazakhstan, in eastern Brazil and central Argentina and in Mexico and the US Midwest as well as almost all of Australia. Clearly, very low sensitivity can be found in the extreme deserts (e.g. the Sahara) as well as in the tropical rainforest belts of Amazonia, Congo and Indonesia. The uncertainty of the sensitivity as shown in Fig. 13 shows no significant pattern and appears to be independent of the areas of particular sensitivity which are mostly rather reliable.
Fig. 11. Global pattern of the sensitivity of NPP towards climate change. (average of 15 gradients) $\left(\mathrm{kgC} \mathrm{m}^{-2} \mathrm{yr}^{-1} \sigma^{-1}\right)$

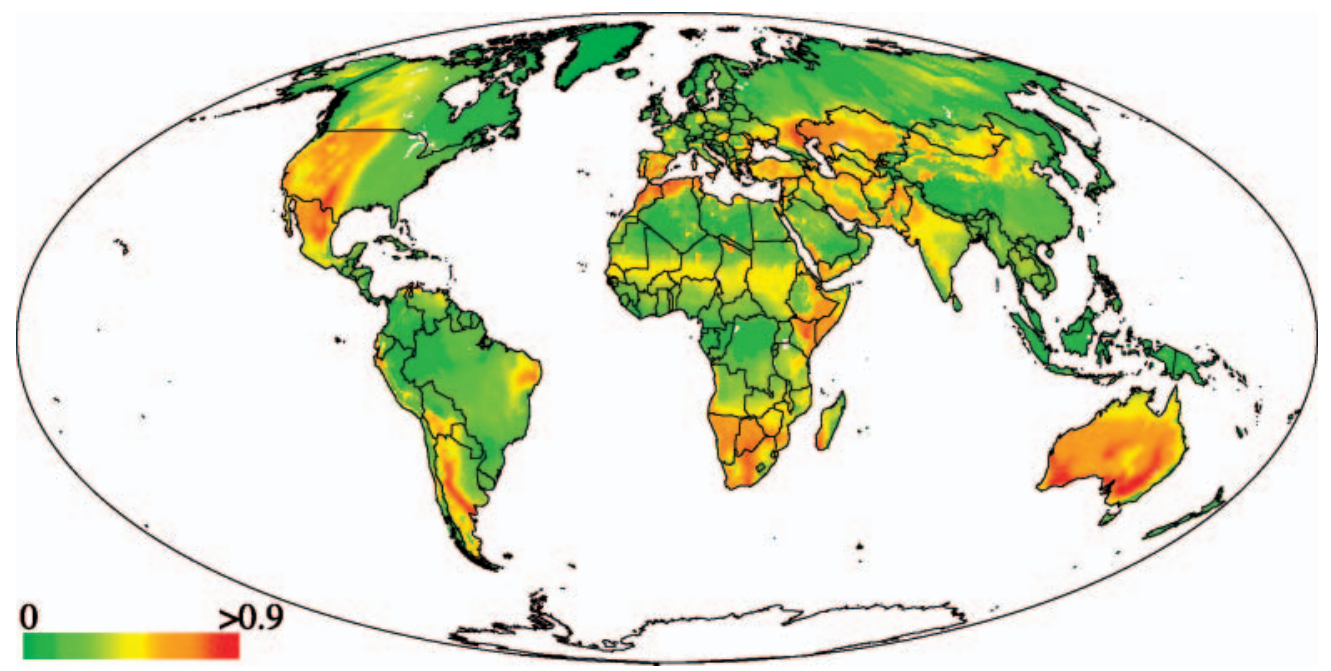




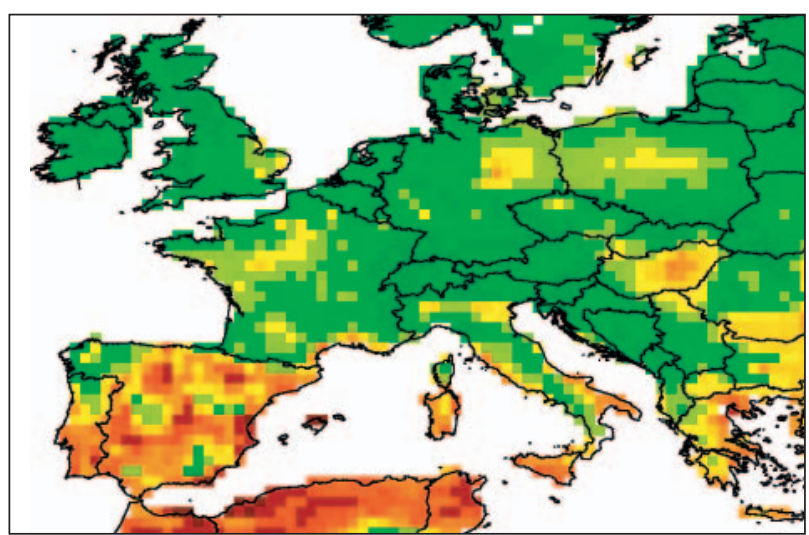

Fig. 12. An enlargement of Fig. 11 showing a part of Europe $\left(\mathrm{kgC} \mathrm{m}^{-2} \mathrm{yr}^{-1} \sigma^{-1}\right)$

As can be seen in Fig. 11, high sensitivity correlates well with semi-arid regions such as those depicted in orange in Fig. 8. To the first order, this is explainable by the fact that spatial rainfall variation constitutes a very large part of the total variation in the climate data after the removal of the direct latitudinal and altitudinal effects by the use of Eq. (1). In the very arid regions, such as the Sahara, and the other regions shown in red in Fig. 8, the sensitivity is very low, because a small change in the climate variables will still not enable much vegetation growth. Similarly the humid areas (e.g. Amazonia) are equally relatively insensitive, since there precipitation is so plentiful that a small change will not diminish NPP. This explanation does of course exclude other variables which can also be very important, such as the temperature in far northern latitudes, where vegetation is mainly limited by temperatures that are too low.

The fact that the sensitivity in the Sahel is considerably lower than in other semi-arid parts of the planet, such as southern Africa or the western US, is somewhat unexpected at a first glance. It can be explained using the observation that the main difference between the middle-sensitivity values in the Sahel and the very high sensitivity regions is how pronounced the rainy season is: the Sahel has a very large ratio of monthly rainfall in the rainy season to rainfall in the dry season, whereas in southern Africa this intraannual variation is much lower. In other words, in the Sahel there are in each year some months where rainfall is much lower than needed for significant NPP and in other months it is too high to act as a strongly limiting factor. As argued above for the cases of desert regions and very humid regions, this tends to cause sensitivity to be lower than that of semi-arid regions with less variable rainfall, i.e. those which have relatively low precipitation throughout the year.

Knowing about the difficulties in the description of rainfall with high interannual variation, we were at first quite doubtful about this result, as it could be that, for example southern Africa has an intra-annual variability in rainfall as high as that of the Sahel, but, as the rainy season is not as regular as in the Sahel (where it occurs in the same months every year), this variability might be hidden by the averaging process during the assemblage of the climatology used here. To check for this interannual averaging problem, we took a climate data set with climate normals for each month in the years 1931-1960 (New et al. 1999) and averaged the precipitation in such a way that the months in each year were shifted until the rainy season was in the same month for each year (similar to the procedure described in Lüdeke et al. 1994) and used this data to recalculate the climate sensitivity of the NPP as described in this section, including the calculation of another set of principal components and the necessary transformations. This whole procedure, however, had no effect on the overall picture of sensitivity; the Sahel was again significantly less sensitive than other semi-arid areas. Therefore we have a considerable degree of confidence in the result depicted in Fig. 11.

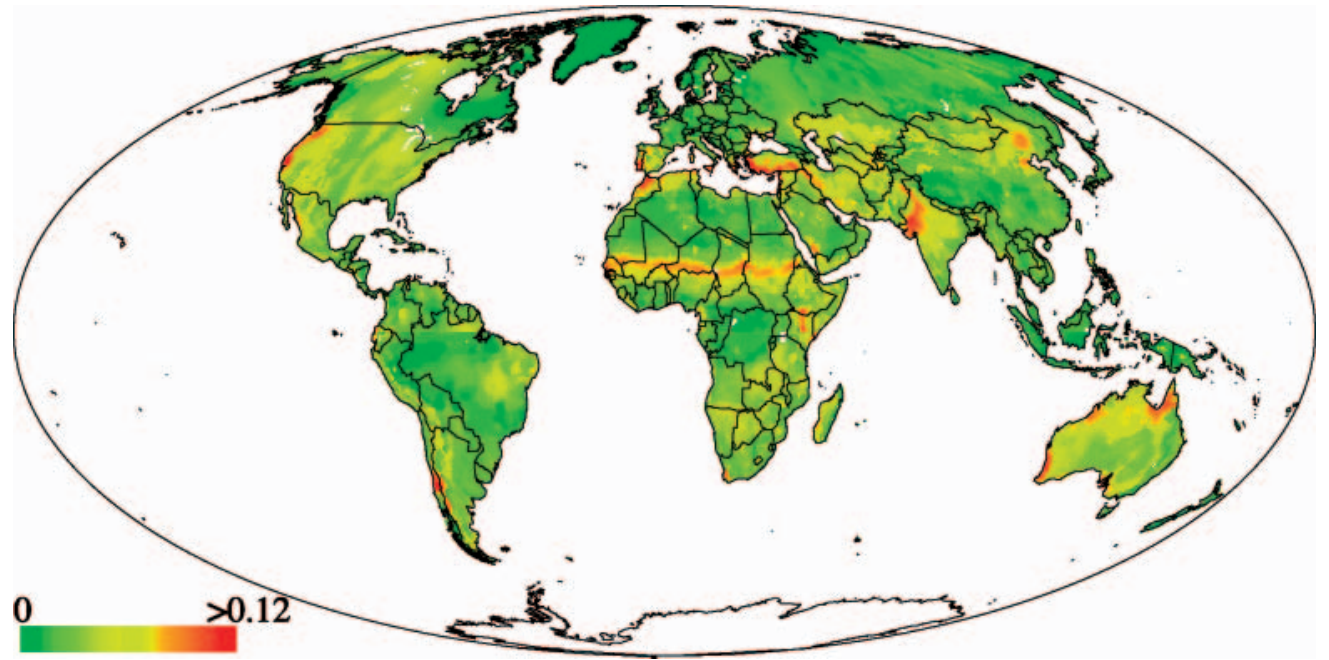

Fig. 13. Uncertainty of the evaluation of climate sensitivity as indexed by the standard deviation of the gradients of the 15 different instances of the ANN ( $\left.\mathrm{kg} \mathrm{C} \mathrm{m}^{-2} \mathrm{yr}^{-1} \sigma^{-1}\right)$. Mediterranean climates and semi dry regions display peak uncertainty 


\subsection{Country-specific sensitivity}

To make the result shown in Fig. 11 useful for policy analysis,we aggregate the sensitivity to the country level. The simplest estimate of country-specific sensitivity would be the spatial average of the sensitivity of each country. However, since the areas with very low productivity are generally of lesser importance to the countries, we excluded from our analysis all pixels with an NPP of less than $0.1 \mathrm{~kg} \mathrm{C} \mathrm{m}^{-2} \mathrm{yr}^{-1}$ (i.e. $23 \%$ of all pixels) and averaged the remaining pixels for each country. This is of course only a rough estimate of the sensitivity of each country's vegetation concerning climate change, e.g. it does not take into account the impact of irrigation and water flows on vegetation, and it considers the different importance of different land areas only very roughly. This country-specific analysis can therefore only be regarded as a first try. However, according to our knowledge, it is the first attempt to define and calculate country-specific vegetation sensitivity concerning climate change. The results can be seen in Fig. 14 and Table 3.

\section{CONCLUSION AND OUTLOOK}

The main results of the presented study consist of: (1) the NNN, a neural network based model for the very fast calculation of NPP, and (2) a new method for the definition and evaluation of the climate sensitivity of NPP, which has been aggregated to the country level.

The NNN model presented here can be seen in the tradition of the Miami model (Lieth 1975); the climate characterization was extended from annual precipitation and annual mean temperature to monthly values (now including light intensity) and the 'training set' for a non-linear parameterized function was extended from about 100 observed NPP values to about 50000
Table 3. Estimates of sensitivities of net primary production towards climate change of some of the 150 countries considered in this study. An asterisk denotes countries where despite the exclusion of low production areas large inhomogeneities occur, implying careful interpretation of the average values

\begin{tabular}{|lcl|}
\hline Rank & $\begin{array}{c}\text { Sensitivity } \\
\left(\mathrm{kg} \mathrm{C} \mathrm{m}^{-2} \mathrm{yr}^{-1} \sigma^{-1}\right)\end{array}$ & \\
\hline 1 & 0.71 & Country \\
2 & 0.70 & Algeria \\
3 & 0.70 & Tunisia \\
4 & 0.68 & Morocco \\
5 & 0.66 & Botswana \\
6 & 0.65 & Sibydi Arabia \\
7 & 0.65 & Namibia \\
8 & 0.62 & Somalia \\
9 & 0.61 & Oman \\
10 & 0.61 & Jordan \\
11 & 0.61 & Australia* \\
12 & 0.60 & Syria Republic \\
13 & 0.60 & Yemen \\
14 & 0.58 & South Africa \\
15 & 0.58 & Egypt \\
17 & 0.58 & Israel \\
18 & 0.56 & Pakistan \\
19 & 0.56 & Iran \\
20 & 0.55 & Kenya \\
24 & 0.54 & Mexico \\
25 & 0.53 & Spain \\
29 & 0.50 & Turkey \\
36 & 0.45 & Argentina \\
48 & 0.38 & India \\
49 & 0.37 & United States* \\
59 & 0.34 & Italy \\
64 & 0.30 & Nigeria \\
73 & 0.27 & France \\
76 & 0.26 & China* \\
77 & 0.26 & Bangladesh \\
91 & 0.23 & Germany \\
92 & 0.23 & Canada* \\
95 & 0.22 & Brazil* \\
107 & 0.20 & United Kingdom \\
114 & 0.19 & Zaire \\
119 & 0.17 & Philippines \\
121 & 0.17 & Brunei \\
145 & 0.10 & \\
150 & 0.07 & \\
& & \\
\hline & & \\
\hline
\end{tabular}

Fig. 14. Average of the sensitivity of NPP towards climate change as shown in Fig. 11 for each country, neglecting the effect of desert areas

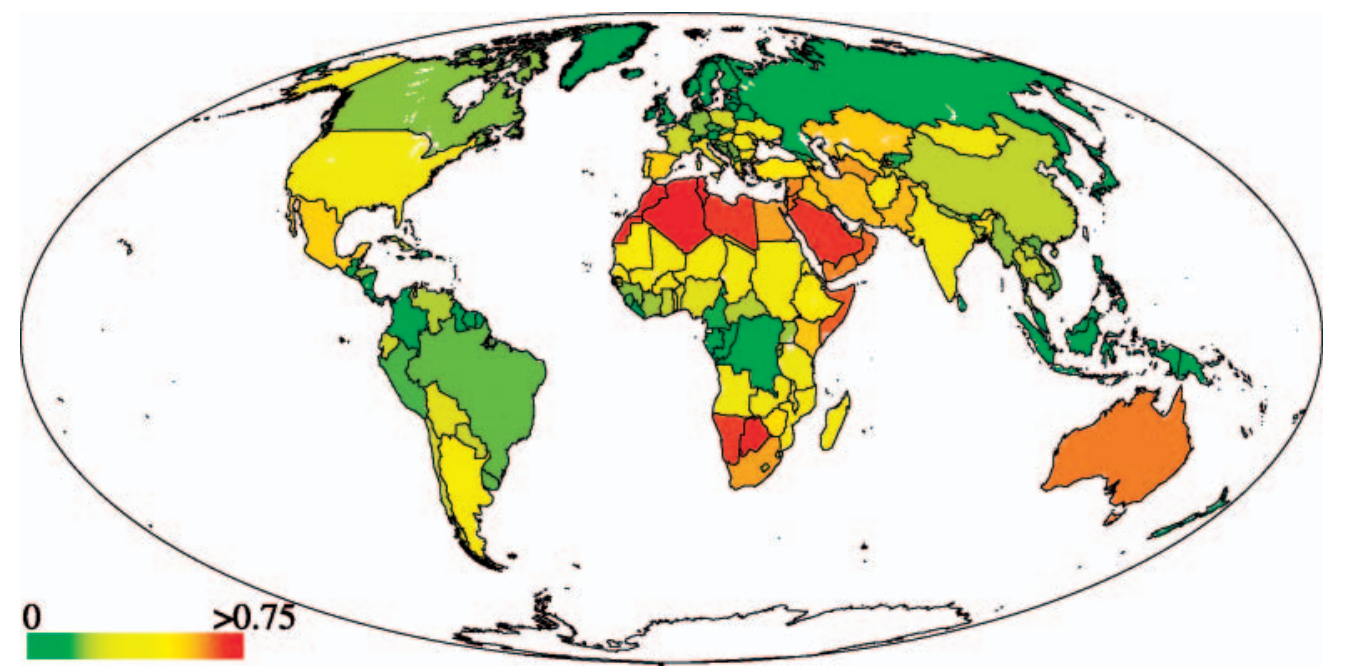


NPP values, which were generated using functional global vegetation models as 'intelligent interpolation tools' of several hundred observed NPP values so far.

Of course one has to keep in mind the general limitations of the 'quasi-static' approach (series of equilibrium results) used in this study for climate impact analysis. A next step could therefore be the development of a simple model which in a similar manner reproduces the expert consensus on the transient behavior of global plant productivity. Here, the results from non-equilibrium biogeochemical models (e.g. the FBM [Lüdeke et al. 1994]: time scale of days to several decades) to dynamic vegetation models (e.g. IBIS [Foley et al. 1996]: time scale of days to centuries) could provide the knowledge basis for another 'reduced-form model' which would probably be based on simple differential equations, as, for example developed for the physical climate system to reproduce the 'essence' of the results of complex GCMs (Hasselmann et al. 1997).

A worthwhile extension in the quasi-static framework would be the inclusion of the $\mathrm{CO}_{2}$ fertilization effect into the statistical model based on the average of the equilibrium NPP predictions of the considered functional vegetation models in a doubled- $\mathrm{CO}_{2}$ climate. One problem is that the expert disagreement in this case is much greater than in the case of today's NPP field. The method would be to include 1 additional independent variable, the atmospheric $\mathrm{CO}_{2}$ con- centration, and extend the training set by a second global NPP field.

As for the second main result, we have defined and calculated, to our knowledge for the first time, a global NPP climate-sensitivity map, independent of specific climate scenarios. This permits a detailed description of regions with a high potential for being affected by climate change, which includes, in the worst case, a decisive negative effect for the NPP of a given region. The aggregation to the country level in a way that corrects for the effects of the very insensitive deserts makes these results applicable to policy analysis.

Widening the scope of this particular study, the method applied here may be used in general to deduce the climate sensitivity of sufficiently detailed expertguess-fields, originating from different models (as in this paper) or from interpolated observations.

Acknowledgements. We gratefully acknowledge Gerd Esser, Jörg Kaduk, Gundolf Kohlmaier, Bill Parton, Matthias Plöchl, Colin Prentice and Ian Woodward together with their collaborators, who provided their NPP results for this study. Furthermore we thank Jürgen Kropp for advice in the 'alchemy' of neural network use, and, again, Jörg Kaduk for very helpful discussions on the mathematics of the neural network used here. Also, we acknowledge Andreas Zell and his group for supplying the Stuttgart Neural Network Simulator, SNNS (Zell 1994), which was used for the design and training of the neural net described here. This work was supported in part by the German Federal Ministry for Education, Science and Technology under Grant Number 01LG9401.

Appendix A. Mean absolute, mean square and maximum absolute error of the NPP-model average

Let us assume that $\mathrm{NPP}_{i}^{\text {obs }}, i=1, \ldots, N$, is a set of $N$ correctly observed NPP values which would allow a complete verification of the results of $M$ different vegetation models, $\mathrm{NPP}_{i}{ }^{k}$, $k=1, \ldots, M$ (which is unfortunately not possible yet). Then:

$$
\bar{f}_{k}^{\mathrm{abs}}=\frac{1}{N} \sum_{i=1}^{N}\left|\mathrm{NPP}_{i}^{\mathrm{obs}}-\mathrm{NPP}_{i}^{k}\right|
$$

would be the mean absolute error of vegetation model $k$. After averaging the models for every point $i$ :

$$
\mathrm{NPP}_{i}^{\mathrm{avg}}=\frac{1}{M} \sum_{k=1}^{M} \mathrm{NPP}_{i}^{\mathrm{k}}
$$

one obtains for this NPP distribution the following mean absolute error:

$$
\begin{aligned}
\bar{f}_{\mathrm{avg}}^{\mathrm{abs}} & =\frac{1}{N} \sum_{i=1}^{N}\left|\mathrm{NPP}_{i}^{\mathrm{obs}}-\frac{1}{M} \sum_{k=1}^{M} \mathrm{NPP}_{i}^{k}\right| \\
& =\frac{1}{N} \sum_{i=1}^{N}\left|\frac{1}{M} \sum_{k=1}^{M}\left(\mathrm{NPP}_{i}^{\mathrm{obs}}-\mathrm{NPP}_{i}^{k}\right)\right| \\
& \leq \frac{1}{M} \sum_{k=1}^{M}\left(\frac{1}{N} \sum_{i=1}^{N}\left|\mathrm{NPP}_{i}^{\mathrm{obs}}-\mathrm{NPP}_{i}^{k}\right|\right) \\
& =\frac{1}{M} \sum_{k=1}^{M} \bar{f}_{k}^{\mathrm{abs}} \\
& =\left\langle\bar{f}_{k}^{\mathrm{abs}}\right\rangle
\end{aligned}
$$

which means that the mean absolute error of the averaged model result, $\bar{f}_{\mathrm{avg}}^{\mathrm{abs}}$, is smaller than (or equal to) the average of the mean absolute errors of the single models, $\left\langle\bar{f}_{k}^{\text {abs }}\right\rangle$. Therefore it is advantageous (or neutral, in the unlikely case that all models homogeneously under- or overestimate $\mathrm{NPP}_{i}^{\text {obs }}$ for all locations $i$ ) to take the average of the model results instead of using one arbitrarily chosen model. To illustrate the above arguments, a simple numerical example for one grid element $(N=1)$ and 3 models $(M=3)$ is given in Fig. 15 . A similar argument holds for the mean square error $\bar{f}_{\mathrm{avg}}^{\text {sqr }}$ of the averaged 'best guess':

$$
\begin{aligned}
\bar{f}_{\mathrm{avg}}^{\mathrm{sqr}} & =\frac{1}{N} \sum_{i=1}^{N}\left(\mathrm{NPP}_{i}^{\mathrm{obs}}-\frac{1}{M} \sum_{k=1}^{M} \mathrm{NPP}_{i}^{k}\right)^{2} \\
& =\frac{1}{N} \sum_{i=1}^{N}\left(\frac{1}{M} \sum_{k=1}^{M}\left(\mathrm{NPP}_{i}^{\mathrm{obs}}-\mathrm{NPP}_{i}^{k}\right)\right)^{2} \\
& \leq \frac{1}{N} \sum_{i=1}^{N} \frac{1}{M} \sum_{k=1}^{M}\left(\mathrm{NPP}_{i}^{\mathrm{obs}}-\mathrm{NPP}_{i}^{k}\right)^{2} \\
& =\frac{1}{M} \sum_{k=1}^{M} \bar{f}_{k}^{\mathrm{sqr}} \\
& =\left\langle\bar{f}_{k}^{\mathrm{sqr}}\right\rangle
\end{aligned}
$$

using the relation:

$$
\left(\frac{1}{M} \sum_{k=1}^{M} \alpha_{k}\right)^{2} \leq \frac{1}{M} \sum_{k=1}^{M} \alpha_{k}^{2}
$$

which holds true for all $\mathbf{a} \in \mathbb{R}^{M}$. 
Appendix A (continued)

With similar arguments, it is possible to show that the expectation value of the maximum absolute error in the case of the arbitrary choice of one model, $\left\langle f_{k}^{\max }\right\rangle$ is greater than the maximum absolute error of the averaged model $\left\langle f_{\mathrm{avg}}^{\max }\right\rangle$. Let:

and:

$$
\begin{aligned}
f_{k}^{\max } & =\max _{i}\left|\mathrm{NPP}_{i}^{\text {obs }}-\mathrm{NPP}_{i}^{k}\right| \\
& =\left|\mathrm{NPP}_{i_{k}}^{\text {obs }}-\mathrm{NPP}_{i_{k}}{ }^{k}\right|
\end{aligned}
$$

$$
\left\langle f_{k}^{\max }\right\rangle=\frac{1}{M} \sum_{k=1}^{M}\left(\left|\mathrm{NPP}_{i_{k}}^{\text {obs }}-\mathrm{NPP}_{i_{k}}^{k}\right|\right)
$$

Then we can identify an upper boundary for the absolute error of the averaged model for an arbitrary point $j$ :

$$
\begin{aligned}
f_{\text {avg }}^{j} & =\left|\mathrm{NPP}_{j}^{\text {obs }}-\frac{1}{M} \sum_{k=1}^{M}\left(\mathrm{NPP}_{j}^{k}\right)\right| \\
& \leq \frac{1}{M} \sum_{k=1}^{M}\left|\mathrm{NPP}_{j}^{\text {obs }}-\mathrm{NPP}_{j}^{k}\right|
\end{aligned}
$$

Comparing Eqs. (6) \& (7), considering Eq. (5), one obtains

$$
f_{\text {avg }}^{\max } \leq\left\langle f_{k}^{\max }\right\rangle
$$

where, again, the equal sign is valid only for very unlikely situations (e.g. in the case that the maximum absolute errors of all models are at the same location).

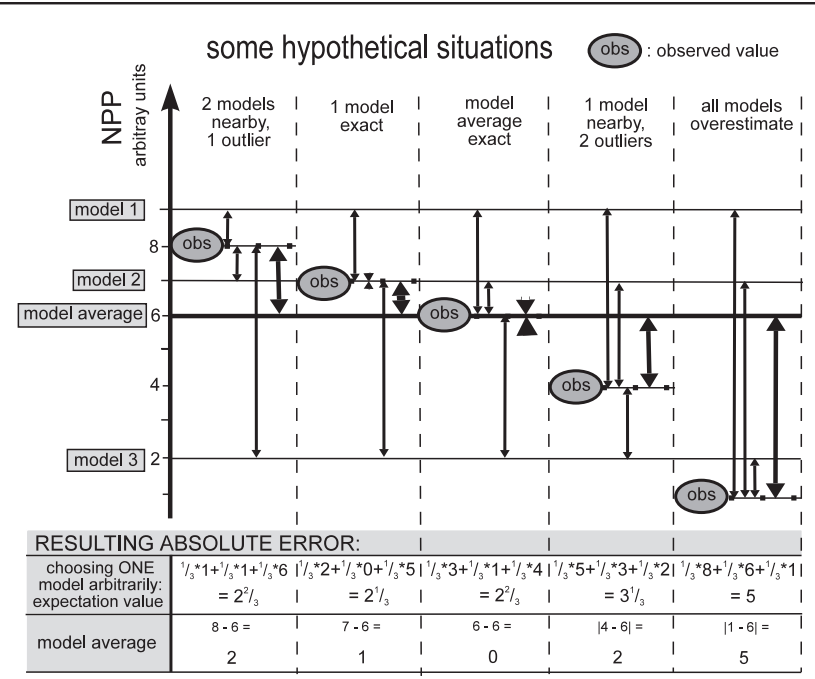

Fig. 15. Example of the advantage of using the average of several models instead of choosing 1 model arbitrarily with respect to the expectation value of the mean absolute error. Without loss of generality a '1 grid element/3 models'example is presented. In this case the 'mean absolute error' becomes a simple 'absolute error'

Appendix B. Structure and function of the neural network

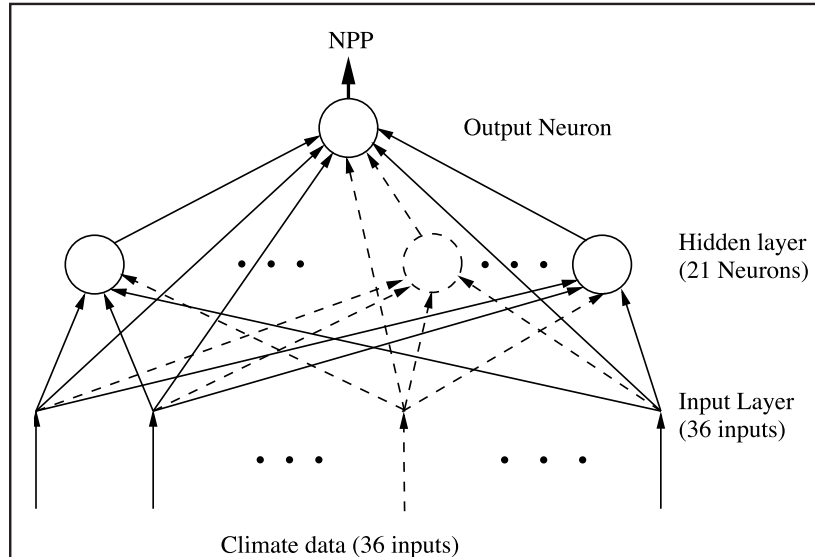

Fig. 16. Structure of the neural network applied for NNN: 36 input nodes for the climatology. Output node: NPP

We use a 3-layer feed-forward ANN as depicted in Fig. 16. In algebraic notation the ANN can be described by:

$$
\begin{aligned}
& \operatorname{NPP}\left(C_{1}, \ldots, C_{36}\right. \\
& =f\left(\theta_{0}+\sum_{k=1}^{36} \omega_{0, k} C_{k}+\sum_{j=1}^{21} \omega_{0, j+36} \cdot f\left(\theta_{j}+\sum_{k=1}^{36} \omega_{j, k} C_{k}\right)\right)
\end{aligned}
$$

where the $C_{k}$ are the 36 climate variables at a given grid cell, $f(x)=\left(1+\mathrm{e}^{-x}\right)^{-1}$ is the so-called activation function, and the 835 different $\omega$ and $\theta$ are the parameters that allow the function to be fitted to the data by the back-propagation learning algorithm.

The climate and NPP data were normalized between 0 and 1 independently for each of the 36 variables. Using the data for the 64283 grid elements for which climate data and NPP model output were available, we formed a training set (49964 grid elements) and a test set (North America: 12519 grid elements). The 835 parameters were initialized randomly between -1 and 1 . The approximation of the optimal parameterization was made using the standard online back-propagation algorithm, which tries to minimize the mean square error between the ANN and the training set, based on steepest descent. The ANN is 'trained' with 30000 training cycles, each using all 49964 data points, with the step size parameter (Zell 1994) decreasing from 0.1 to 0.008 . The parameter sets which best fit the test set found during the training were chosen and the best of these for 30 different runs is described here as NNN, while the 15 best instances are used to calculate the climate sensitivity and its standard deviation as shown in Figs. 11 \& 13.

We also tried various other ANN topologies, including ANNs without direct connections between the input and the output layer, ANNs with 2 hidden layers, ANNs with less nodes in the hidden layer and ANNs with radial basis functions instead of 'neurons', with various numbers of radial basis functions (the centers of the radial basis functions were found using self-organzing maps; Kohonen 1997); but all these networks were inferior to the 3-layer ANN used here in their ability to reproduce the training and test set. 
Appendix C. 2-dimensional example for the double transformation described in Section 3.2

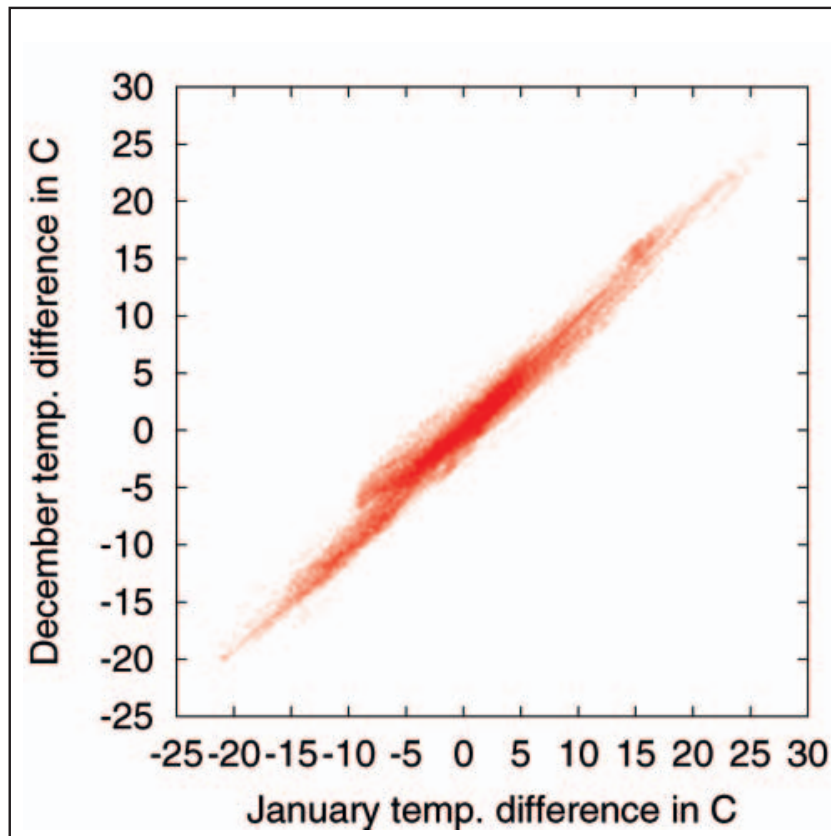

Fig. 17. January and December temperatures as taken from CLIMATE2.1 and corrected for insolation and altitude as shown in Eq. (1)

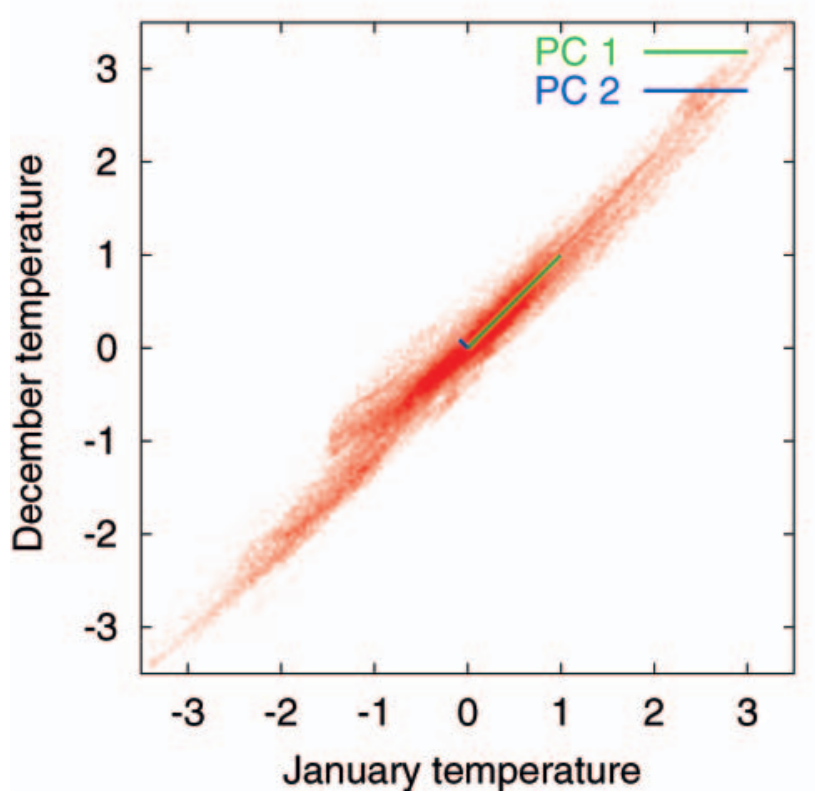

Fig. 18. January and December temperatures as in Fig. 17 after the $z$-transformation. The data is measured here in standard deviations. The green and blue lines show the direction and length of the 2 principal components
To illustrate the double transformation used in Section 3.2 (firstly a $z$-transformation and then a transformation into principal component space), we have calculated an example of this procedure in 2 dimensions, since the procedure in the whole 36-dimensional space is difficult to visualize. As sample variables, we took the January and December temperatures, corrected as described in Section 3.1. As can be seen in Fig. 17, the 2 temperatures are very closely correlated. Fig. 18 shows the temperatures after the $z$-transformation, together with the 2 principal components describing this data. Now the data is measured in standard deviations, making these temperatures directly comparable, both mutually and to other variables such as precipitation. The first principal component calculated by the PCA is parallel to the main direction of the 'data cloud', while the second, explaining much less variance, is perpendicular to the first. The length of both principal components is equal to the standard deviation of the data projected on them. Using these 2 principal components as unit vectors, we transform the data into principal component space as shown in Fig. 19. Now the 'data cloud' no longer shows any systematic direction and is as circular as possible using linear transformations; this is exactly what is needed to make our gradient approach, which weighs each axis identically, feasible. If we had taken the data 'untreated' as in Fig. 17, the result would depend on the units used, and even after the $z$-transformation (Fig. 18), a straightforward calculation of the gradient would have overestimated the importance of changes occurring in less likely directions, e.g. January temperature increasing as much as December temperature decreases.

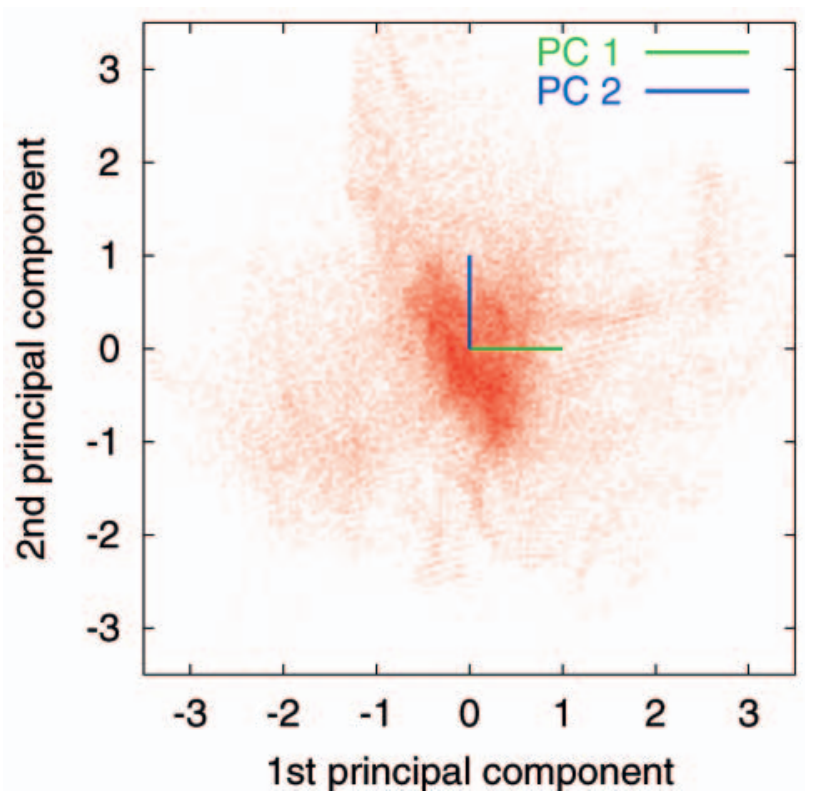

Fig. 19. As for Fig. 18, but after the projection of the data onto the 2 principal components. This projection trivially transforms the 2 principal components onto the first and second unit vectors (shown again in green and blue) 


\section{LITERATURE CITED}

Alcamo J (ed) (1994) IMAGE 2.0: Integrated modelling of global climate change. Kluwer Academic Press, Dordrecht

Cassel-Gintz M, Lüdeke MKB, Petschel-Held G, Reusswig F, Plöchl M, Lammel G, Schellnhuber HJ (1997) Fuzzy logic based global assessment of the marginality of agricultural land use. Clim Res 8:135-150

Ciret C, Henderson-Sellers A (1997) Sensitivity of global vegetation models to present-day climate simulated by global climate models. Global Biogeochem Cycles 11(3):415-434

Cramer W, Kicklighter DW, Bondeau A, Moore B III, Churkina G, Nemry B, Ruimy A, Schluss AL and the participants of the Potsdam NPP model intercomparison (1999) Comparing global models of terrestrial net primary productivity (NPP): an overview and key results. Global Change Biol 5(Suppl 1):1-15

de Noblet N, Prentice I, Joussaume S, Texier D, Botta A, Haxeltine A (1996) Possible role of atmosphere-biosphere interactions in triggering the last glaciation. Geophys Res Lett 23(N22):3191-3194

Esser G, Hoffstadt J, Mack F, Wittenberg U (1994) High resolution biosphere model: documentation model version 3.00.00. Institut für Planzenökologie, Justus-Liebig-Universität Gießen

Foley JA, Prentice C, Ramankutty N, Levis S, Pollard D, Sitch S, Haxeltine A (1996) An integrated biosphere model of land surface processes, terrestrial carbon balance, and vegetation dynamics. Global Biogeochem Cycles 10(4): $603-628$

Hasselmann K, Hasselmann S, Giering R, Ocaña V, von Storch H (1997) Sensitivity study of optimal $\mathrm{CO}_{2}$ emission paths using a simplified structural integrated assessment model (SIAM). Clim Change 37(2):345-386

Haxeltine A, Prentice IC (1996) BIOME3: An equilibrium terrestrial biosphere model based on ecophysiological constraints, resource availability, and competion among plant functional types. Global Biogeochem Cycles 10(4):693-709

Kaduk J, Heimann M (1996) A prognostic phenology scheme for global terretrial carbon cycle models. Clim Res 6:1-19

Kohlmaier GH, Lüdeke MKB, Janecek A, Benderoth G, Kindermann J, Klaudius A (1991) Land biota, source or sink of atmospheric carbon dioxide: positive and negative feedbacks within a changing climate and land use development. In: Schneider SH, Boston PJ (eds) Scientists on Gaia. Cambridge University Press, Cambridge, p 223-239

Kohlmaier GH, Badeck FW, Otto RD, Häger C and 10 others (1997) The Frankfurt Biosphere Model: a global processoriented model for the seasonal and long-term $\mathrm{CO}_{2}$ exchange between terrestrial ecosystems and the atmosphere. Part 2: Global results for potential vegetation in an assumed equilibrium state. Clim Res 8:61-87

Kohonen T (1997) Self-organizing maps, 2nd edn. Springer Series in Information Sciences, Springer-Verlag, Berlin

Köppen W (1931) Grundriss der Klimakunde. Walter de Gruyter Co, Berlin

Kubatzki C, Claussen M (1998) Simulation of the global biogeophysical interactions during the last glacial maximum. Clim Dyn 14:461-471

Editorial responsibility: Gerd Esser,

Gießen, Germany
Leemans R, Cramer W (1991) The IIASA database for mean monthly values of temperature, precipitation and cloudiness of a global terrestrial grid. Tech Rep RR-91-18, International Institute for Applied Systems Analysis, Luxemburg

Levis S, Foley J, Pollard D (1999) Climate-vegetation feedbacks at the last glacial maximum. J Geophys Res Atmos 104(D24):31191-31198

Lieth H (1975) Primary productivity in ecosystems: comparative analysis of global patterns. In: von Dobben $\mathrm{WH}_{\mathrm{r}}$ Lowe-McConnel RH (eds) Unifying concepts in ecology. Junk, The Hague, p 76-88

Lüdeke MKB, Badeck FW, Otto RD, Häger C and 8 others (1994) The Frankfurt Biosphere Model. A global process oriented model for the seasonal and longterm $\mathrm{CO}_{2}$ exchange between terrestrial ecosystems and the atmosphere. Part 1: Model description and illustrating results for the vegetation types cold deciduous and boreal forests. Clim Res 4(2):143-166

Lüdeke MKB, Moldenhauer O, Petschel-Held G (1999) Rural poverty driven soil degradation under climate change: the sensitivity of the disposition towards the sahel syndrome with respect to climate. Environ Model Assess 4(4): 315-326

Melillo JM, McGuire AD, Kicklighter DW, Moore B III, Vorosmarty CJ, Schloss AL (1993) Global climate change and terrestrial net primary production. Nature 363:234-240

New M, Hulme M, Jones P (1999) Representing twentieth century space-time climate variability. II: Development of 1901-1996 monthly grids of terrestrial surface climate. J Clim 12:829-856

Olson RJ, Scurlock JMO, Cramer W, Parton WJ, Prince SD (1997) From sparse field observations to a consistent global dataset on net primary production. IGBP-DIS Working Paper No. 16, Toulouse

Plöchl M, Cramer WC (1995a) Coupling global models of vegetation structure and ecosystem processes. An example from arctic and boreal ecosystems. Tellus 47B:240-250

Plöchl M, Cramer WC (1995b) Possible impacts of global warming on tundra and boreal forest ecosystems: comparison of some biogeochemical models. J Biogeogr 22: 775-783

Prentice IC, Cramer W, Harrison SP, Leemans R, Monserud RA, Solomon AM (1992) A global biome model based on plant physiology and dominance, soil properties and climate. J Biogeogr 19:117-134

Schimel DS, Braswell BH, McKeown R, Ojima DS, Parton WJ, Pulliam W (1996) Climate and nitrogen controls on the geography and time scales of terrestrial biogeochemical cycling. Global Biogeochem Cycles 10(4):677-692

Trewartha GT (1968) An introduction to weather and climate, 4th edn. McGraw-Hill, New York

USNGDC (1988) ETOPO5 Global elevation at 5 minutes resolution. US National Geophysical Data Center, Boulder, CO

Woodward FI, Smith TM, Emanuel WR (1995) A global land primary productivity and phytography model. Global Biogeochem Cycles 9(4):471-490

Zell A (1994) Simulation Neuronaler Netze. Addison-Wesley, New York

Submitted: April 7, 2000; Accepted: April 25, 2001

Proofs received from author(s): March 12, 2002 